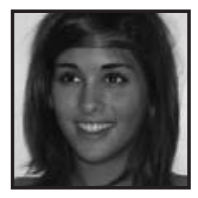

\title{
Arts: Inspiration for Life
}

\section{Anne-Sophie Grenier, Heritage Regional High School}

\section{ABSTRACT}

In this article, the author recounts her experience at Centauri Summer Arts Camp, which has been instrumental in fostering her personal, artistic and spiritual growth. She emphasizes the particular importance of openness, communication, friendship, understanding and acceptance.

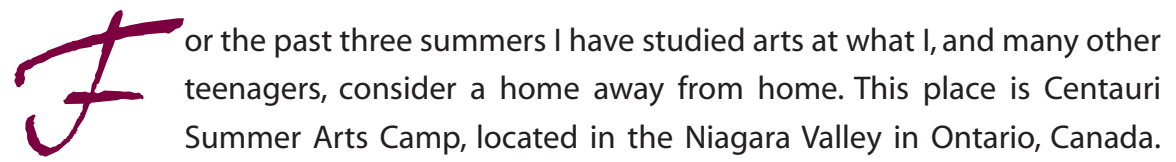
Campers, aged nine to eighteen, specialize in one art form per session, and take workshops in others. I have specialized in Shakespeare theatre, digital photography, film, musical theatre dance and experimental theatre. This summer I studied dance and theatre.

In the three weeks I spend there, I grow as much as I do during the whole year, both as an artist and as a person. This growth is made possible by the way the camp is run. The environment is very nurturing, yet informal enough that we campers feel free to form our own opinions about the world and about art. This comes into the specialized programs, where professionals push us to develop our skills and break our boundaries. We learn to express ourselves in ways that can be easier or more effective through the medium of art than by simply saying what we think. The symbiotic relationship between the social aspect and the arts aspect of camp creates innumerable possibilities for creation, friendships and an all-around good time. 
Emotions, activities, friendships and life in general tend to happen very quickly and on large scales at Centauri. This summer, studying under Toronto-based actor, Christopher Fowler, I learned to use this to my advantage. I learned to understand all the emotions I was feeling and to depict each one. Doing this enabled me to do the same for our script. The play we were working with was Chekhov's The Bear. Understanding the intent in every thought is the key to delivering a believable performance. A lot of the dialogue was related to the Russian culture or was out of date, so the theme of the play was understood through the subtext. For example, in one scene, the two main characters are having an argument over power. The direction in the script during one of the character's monologues was to pause. Because of the arrogance of both characters, we decided to turn it into somewhat of a staring contest. This mimed argument was not only comical, but also let the audience see the difference between both characters through the physical movement we had studied. The man who had been speaking was restless and kept shooting furtive glances at his opponent, while the latter, a woman, remained poised and focused. In the end, the man lost his temper and continued his enraged monologue.

With Mr. Fowler I also learned about the beauty of simplicity. What many actors tend to do in moments of silence is to overact and play the buffoon for the audience. This results in a break of character and is not believable. To stress this point we did an exercise where two campers had to sit in front of the rest of the group and wait. We were waiting for someone we did not want to see, and who was late. There was lots of fidgeting and exasperated sighs. The performances that were the truest were those that had less fidgeting and smaller actions. These worked better because the audience could focus on the actors' face, and imagine the thought behind their eyes.

Since the theatre program was experimental, we looked at directors such as Grotowski and Meyerhold. We studied the physicality of an actor and how "theatrical" a play can be. We also looked at their opposites and the realism of Stanislavsky. This was once again for the purpose of understanding. I learned that whether you are playing a Greek hero, a Shakespearean lover or are eating cucumber sandwiches in an Oscar Wilde play, you have to understand why you are saying the lines and the intent behind the words. Whether the director chooses to keep the play in the world of realism or break the fourth wall and create an "experimental" play, the emotions are still the same and just as important.

Centauri as a whole could not exist without the arts component but it could not exist without the social component either. There are many other art camps, but 
the emphasis on friendship and understanding lifts us to a superior level to create and perform. Friends inspire each other, often without even realizing.

I have had the pleasure of meeting people from all around the world and all different walks of life. I have friends in Uganda, Switzerland, Japan, Mexico, Texas, New York, Halifax and elsewhere. In such a varied social context, one would expect many disagreements. But Centauri is perhaps the most accepting place I have ever been. Everyone I have asked agrees that a lot of the pressure they feel back home can be forgotten during their stay. We tend to focus more on the positive qualities of those around us and appreciate them for who they are.

There is a special bond formed between campers, counsellors and senior staff. I don't know how to describe this bond except with the word love. During the year, camp friends make the effort to take a train or a road trip to visit one another. I would hitchhike across Canada to see some of my summer friends if I had no other way. My best friend and I send each other birthday and Christmas presents, and thanks to Facebook, I am in regular contact with my fellow campers. A counsellor I had in 2006 once told me that she had lost contact with most of her high school friends, but is still close to her camp friends, and always will be.

What is special about this bond is truthful communication. We compliment each other throughout the day. This isn't to be hypocritical, but because we appreciate each other, and aren't afraid to show it. I stayed for two sessions this summer and thus had two bunkmates. On the last night of both sessions, we told each other why we appreciated the other, what made them special. I, like many my age, have a fear of showing my true emotions. This vulnerability seems to leave when I arrive at camp because I feel safe.

The counsellor I had this summer, who is currently studying English and Art History at McGill, is now like an older sister to me. It isn't that we have anything huge in common; it was all the little things she did that make her special. Every night, she would play her guitar and sing to the dorm. Coincidentally, she knew all of our favorite songs. Then she would tuck us in and talk to us one on one. Being a teenage girl, I was dealing with situations with boys and was worrying about my senior year and everything I had to do. She would always listen, and I knew she was genuinely interested in helping me. When we weren't having heart to heart moments, everything she said was hilarious. She inspires me to be a generally happier person, to be a better sister and friend, and to one day be a counsellor. 
The most mature sixteen year old I have ever had the pleasure of knowing is one of my friends, Amelia (pseudonym). She has a deep understanding of social behavior. One day, one of our friends was very upset and we were all trying to console her. Amelia didn't say anything but just gave her a big hug and looked her in the eyes. This had a more uplifting effect than anything that was said, just because it was an act of love and understanding. Amelia still enjoys her youth and everything it brings, but has inspired me to look at the bigger picture. Her goal in life is to reach the Buddhist principle of enlightenment.

I think that because camp is so short compared to the rest of the year, we take advantage of every moment and live life to the fullest. All the organized activities become canvases on which to form friendships and somewhat "wild" memories; the people we live with make our creations deeper and more personal. All the campers, whether or not they were best friends or whether they never met, share a connection through what they learned in their art, what they learned about others and what they learned about themselves.

This is but a brief overview of the time I have spent at Centauri. Had I explained all the different aspects and shared my favorite memories, there would be no place left in the journal for anything else. I shall always cherish what I learned there and the friends I made. Saying a final good-bye this summer was extremely difficult, and I hope to one day find a place in the world as beautiful and genuine as my summer home.

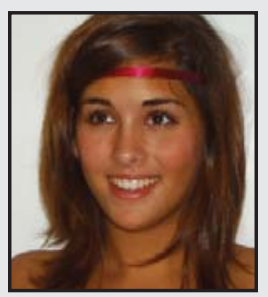

Anne-Sophie Grenier is a sixteen-year-old honour student in the International Baccalaureate program at Heritage Regional High School in Quebec. Her favourite classes are world history and English. She loves reading, movies, museums, theatre, live music and traveling. Her favourite musical artists are The Beatles and M.I.A. She is a Heritage Huskies cheerleader and loves playing sports of all kinds and dancing.

LINK TO:

www.centauri.on.ca 